A New Student Learning Focus for the Academic Library:

From Geographical Proximity of the Learning Commons to

Organizational Proximity within the Library

Jo Ann F. Murphy

University of Saskatchewan, Saskatoon, SK. Canada 


\section{A New Student Learning Focus for the Academic Library: From Geographical Proximity of the Learning Commons to Organizational Proximity within the Library}

Abstract: In 2015 student learning programs at the University of Saskatchewan moved organizationally to the university library. While these services resided physically in the library as part of the Learning Commons partnership, this recent change presents the library with a new focus and responsibility for broader student learning support and academic skill development.

Highlighting examples of organizational integration of student learning support, this article uses a proximity perspective, suggesting that geographical proximity of services in the learning commons does not go far enough to achieve the deeper collaboration and integration necessary for holistic and integrated learning, and that organizational proximity is needed.

Keywords: Learning commons, integrated learning, learning services, learning skills, organizational change, geographical proximity, organizational proximity, cultural proximity, cognitive proximity,

Author's note: Jo Ann F. Murphy is Head, Student Learning Services and Head, Science and Engineering Libraries at the University of Saskatchewan, Saskatoon, Canada. Send communication to author at Rm 106.0 Murray Building, 3 Campus Drive

Saskatoon, SK. S7N 5A4. Email: joann.murphy@usask.ca.

Received: May 1, 2017

Accepted: July 14, 2017 


\section{A New Student Learning Focus for the Academic Library: From Geographical Proximity of the Learning Commons to Organizational Proximity within the Library}

The question about new roles for libraries and librarians has been a hot topic both within and outside the profession. Some speculate about the demise of libraries, when in fact quite the opposite is happening. Libraries, librarians, and professional associations are actively embracing library transformation in order to remain relevant and to remain leaders of change within the communities they serve. The academic library is a central hub for seeking information, research support, study, and information literacy instruction. With an abundance of digital content accessible from a distance, libraries are creating innovative learning spaces and pursuing collaborative partnerships to provide new services and programs within the library. As a result, the library has increasingly become a central hub not only for traditional library services, but also more broadly for other learning services, academic support, and student engagement activities.

The LC partnership philosophy has been instrumental in this change. With co-location of services, the LC brings expertise together in a central location, typically the library. This seamless learning environment aligns with a growing trend in higher education focused on holistic and integrated learning. While the LC model has been successful, partnerships with other units have limitations and are not without their challenges. From the student perspective, physical proximity and access to these services is essential but a lack of organizational proximity, including shared culture, mindset, and unit priorities, can be a barrier to deeper collaboration. Transformation of the academic library though, from a book-centered to learnercentered space, and the evolution of the LC partnership model, with its co-location of services, has paved the way to reimagine a new focus bringing student learning programs and services into 
the library organization. At the University of Saskatchewan, such an organizational change has occurred. The library is now in a position to consider a broader learning mandate to include academic literacies and learning skills along-side information literacy and research skills.

\section{Organizational Change at the University of Saskatchewan}

The University Library at the University of Saskatchewan is an academic (nondepartmentalized) college with a dean, two associate deans and librarian faculty. In May 2015, the University of Saskatchewan's student-focused learning programs became part of the library. Eight employees responsible for providing learning support moved organizationally to the library. The integration came about because of university priority planning that mandated a reorganization of centrally organized teaching and learning activities and functions. Prior to this transition, student learning support programs were core services within the University Learning Center (ULC) reporting through the Office of the Vice-Provost, Teaching and Learning, along with Student and Enrollment Services Division, the Center for Teaching Effectiveness, Media Production Services, and the Distance Education Office. The ULC office and services were physically located within the Murray Library Branch, participating as a partner in the LC. With the merger, a new unit called Student Learning Services was created with both former ULC employees and some library employees reporting to a librarian unit head. Services remain in the existing location within the Murray Branch of the library, offering all of the support programs it had prior to the reorganization. 


\section{Information Commons to Learning Commons}

The university moved toward a LC model with the establishment of the University Learning Center (ULC) in 2007. The mission of the ULC was to transform teaching and learning for students. During this period, two floors of the Murray Library underwent a renovation to accommodate ULC offices and to incorporate a collaborative learning design, including shared teaching and learning spaces, student study rooms, a technology-enhanced collaborative learning lab, assistive technology room, coffee shop, and an after-hours safe study area. The University Library and ULC were key partners in the Learning Commons (LC), along with Information and Communication Technology Services, Disabilities Services, and Consumer Services. Prior to this initiative, in 2001, the library and campus IT had established a partnership providing an enhanced online environment with shared support from IT and Library Help Desks located in the library. This earlier approach models an Information Commons (IC) described by Beagle (1999) as "an exclusively online environment in which the widest possible variety of digital services can be accessed via a single graphical user interface..." (p. 82) located in a "new type of physical facility specifically designed to organize workspace and service delivery around the integrated digital environment...” (p. 82). Evolving from the IC, the LC philosophy is a co-operative partnerships model with emphasis on co-location of services supporting student learning. Beagle (2004) identifies this evolution as a "developmental model" based on a "typology of change" from adjustment to isolated change, far-reaching change, and transformation, whereby the change from IC to LC happens at the far-reaching phase, with the library and other campus units working to align learning initiatives with campus-wide priorities. 
Beagle (2004) states,

An IC goes through a phase transition to become a Learning Commons when it ceases to be primarily library-centric, as when its resources are organized in collaboration with learning initiatives sponsored by other academic units, or aligned with learning outcomes defined through a cooperative process... By integrating those functions formerly carried out within the library with others formerly carried out beyond the library's purview, the service profile is no longer library centric, and becomes essentially collaborative (p. 2).

A LC incorporates various campus units sharing physical space to provide learning support in a "one-stop shop" approach. These collaborations do not necessarily look the same in every institution. Accardi, Cordova, and Leeder's (2010) framework maps the evolution of the LC concept, the partnership model and the administrative logistics that are required for a successful LC. While each institution will be unique in what it offers as part of their LC, what is central to the model is bringing together services and programs to support student success and learning. LCs typically provide a variety or combination of technology services, student services, student success, or learning support programs such as writing and math help and study skills. Partnerships with other units might include teaching and learning centers, career centers, and residence life programs among a range of other possibilities. For some, the service mission may go beyond the shared physical space with a level of collaborative programming delivered within the commons area or possibly in a classroom setting. While a LC does not necessarily have to exist within the library, in most instances that is where it is located. In some cases, a newly built facility will house various campus partners occupying space and delivering service from within. Such a facility may or may not be called a LC, but it functions in much the same way. Often, 
management and oversight for such facilities remain with the library along with a range of library services, sometimes with collection space, albeit significantly reduced.

To understand why the LC naturally found a place in libraries, it is important to consider what Bennet (2009) has identified as a history of paradigm change for academic libraries. This paradigm starts with the Reader-Centered Paradigm, where "books are decisively in the service of readers" (p. 182) and "were few and precious" (p. 182). Then moving to the Book-Centered Paradigm with books dominating the space, eventually becoming "less congenial to readers" (p. 185), and ultimately driving readers out of the space to accommodate collection growth. Finally, Bennet (2009) highlights the Learner-Centered Paradigm, which puts the learner at the center of library and campus space planning. This "is a return to the first paradigm, with the critical differences that information is now superabundant rather than scarce and now increasingly resident in virtual rather than in physical space" (p.187). Essentially, the digital age and access to electronic resources has shifted the balance away from academic libraries building physical warehouses of print material to libraries focused on bringing the campus community back into the library.

In all three paradigms, the academic library has always supported learning, the difference being that in the first paradigm, support for learning was focused on creating space to interact with information and to study. In the second paradigm, the library had to ensure there was enough space to collect all the information the learner might need. In the third paradigm, the learner now interacts with information virtually and remotely which allows libraries to consider not just what could fill the space but how to reimagine space to inspire learning and integrate 
services for the learner. The move toward a LC approach, with its collaborative partnership model, coincides with this learner-centered paradigm shift.

While some libraries were early adopters and moved toward an IC or LC more than 30 years ago, others continue to transform their spaces and services to incorporate their own design, focus, and collaborative partnerships that best reflect and represent the needs of their campus community. Depending on the context at each institution and library, what seems to be consistent is the rational for pursuing partnerships is the desire to achieve a seamless learning environment for students (Accardi, Cordova, \& Leeder, 2010, p. 316).

\section{Holistic and Integrated Learning}

The concept of the information and learning commons model as a seamless learning environment is not unlike a broader trend in higher education, focused on a more holistic and integrated approach to education and learning. Whether a library subscribes to the nomenclature of an IC with its predominantly IT focus or a LC defined by its learning support and co-location of services, the evolution of the IC and LC models has provided a context and "set the stage for the ongoing emergence of new learning paradigms" (Beagle, 2012, p. 530). Beagle points out that the "integrative learning movement... is a good example of a $21^{\text {st }}$ century learning paradigm that has already begun intersecting the process of IC and LC development” (2012, p. 532). He suggests "the conceptual language, philosophy, and learning support priorities behind the IC and LC development" (p. 532) might be the mechanism needed for collaborative innovation related to new integrative learning and technology. 
With new technology and online learning, and changing expectations of students who do not always take a linear approach to their education, many institutions are embracing learnercentered practices that are flexible, blended, and embedded within courses (Weaver, 2008). An integrated and holistic approach requires a shift within higher education from a compartmentalized mindset to one that is shared and collaborative. One that sees service units converging with each other and with academics beginning to integrate learning supports within curricula. Roberts and Stewart (2008) argue that convergence of services and roles, often embodied physically within a learning center or learning commons, have more value when philosophically the convergence brings together "different perspectives and practices across the university with the aim of creating a more holistic model of student support" (p. 24). Holistic and integrated learning requires more than just collaboration based on a physical location or a notion of "working together"; what is required is shared experience and an understanding of each other's professional roles, philosophy, goals, and values (p. 29).

A collaboration between the library and student learning support services (SLSS) at Victoria University of Wellington is characterized by, a "strong joint philosophical approach built on the principle of holistic practice" (Roberts \& Stewart, 2008, p. 26). Beyond the shared physical space with an SLSS help desk positioned within proximity to the library information desk, the two units are moving toward a longer- term partnership by participating in joint action planning, staff development opportunities, regular shared staff meetings, and meetings between two senior managers. Collaborative work on specific projects such as new-student orientation, customized workshops for both academic skills and information literacy, and working with academic colleagues are considered pivotal for holistic and integrated learning support. 
The impact of technology on teaching, learning, and academic support services, combined with a learner-centered and holistic pedagogy, has brought with it an increasing expectation for academics to engage and to be concerned in student learning support and academic skill development (Martin, 2008). "The professionalization of learning and teaching and the widespread use of technology have begun to change the traditional perception of the academic from a solitary figure immersed in their discipline and resistant to change, to more of a facilitator of learning” (Martin, 2008, p. 151). Additionally, the growing need for universities to address a deficit in academic skills among students and look toward improving these skills has "resulted in the rapid growth of professional support staff within universities, whose job is to 'fix' the skills 'problem' with what are frequently described as 'bolted-on' skills courses” (Martin, 2008, p. 150). Although the conditions and benefits of incorporating academic literacy skills into courses and curricula have been acknowledged, learning services at many institutions continue to be focused on a remedial process of support for "at risk" students (Gunn, Hearne, \& Sibthorp, 2011, p. 8). Organizationally, and within university structures, these units may report up through a variety of places including student-service divisions, academic units, and teaching and learning centers. In some cases, they may offer front-line support within the library, often as part of a learning-commons structure.

Martin's (2008) review of multi-professional teams in higher education examines the trend toward holistic and integrated learning support bringing together academics, learning technologists, academic skills advisers, academic librarians, and in some cases education developers and IT/computing staff. These teams can be "described as multi-professional, multidisciplinary, hybrid, multi-skilled, and/or cross-functional" and should not be "confused 
with individuals or groups who simply consult or liaise together over a period of time" (p. 153). The latter were often associated with the learning commons model. Martin (2008) suggests members of multi-professional teams come together with a defined purpose, and shared aim, and with expert skills that complement each other. The desired result of these collaborations is to embed learning supports and to develop academic and information literacy skills as an integral part of the learner's programme of study. Martin (2008) goes on to point out that much of the literature shows the trend for these teams is to be comprised of academics, librarians, and technologists, and less so with study skills or other academic skills advisers, but that "anecdotal evidence suggests, however, that specialist skills centers are beginning to converge with academic library and information services. Such convergence will provide more improved opportunities for collaborating in multi-professional teams" (p. 161).

A high-functioning, multi-professional team, working together to develop holistic and integrated learning into a program, could be considered the hallmark for a transformed learning model in higher education. But the challenges that academics, librarians, learning specialists, educational technologists, and other professionals face when pursuing such collaborations can outweigh the desire or commitment to move in that direction. Members of these teams will come from different reporting units and leadership across campus with competing demands, strategic directions, priorities, time commitments, and resources, but it is often the lack of shared understanding, culture, and mindset within an organizational context that poses a barrier. By converging specialist learning support within the academic library, the potential for consolidated and deeper integration under one umbrella helps to increase the opportunity for successfully embedding holistic and integrated learning into the curriculum. 


\section{A New Learning Mandate for Academic Libraries}

With change in the digital environment driving transformation, libraries are taking the opportunity to not only reimagine services in relation to physical space, but to consider a new learning focus and educational role that contributes to student success, retention, and graduate learning outcomes. The learning-centered paradigm that Bennet (2009) talks about not only places the learner at the center of library design and space planning, but requires librarians to "think more like educators and less like service providers... And, most critically, choose to enact the learning mission of our institutions rather than simply support it" (Bennet, 2009, p. 194). As a result, libraries have become more involved in other campus partnerships, often as leaders in student success strategies and programs such as learning communities, peer tutoring, first-year and first-generation experience initiatives, among others (Association of College and Research Libraries Research Planning and Review Committee, 2016). While this expanded direction may be a new role for the library, there is continued emphasis on developing library research skills, and a renewed imperative for information literacy is stronger than ever. While some libraries continue to struggle to find a place within the educational mission of the academy, others have developed robust information-literacy initiatives with librarians working alongside academic faculty to integrate and embed research skills and resources into course content in a variety of ways, including online and face-to-face. Librarians may even be involved at the level of curriculum development, incorporating information literacy skills as a requirement of program completion or as a stand-alone, credit-based course. The established discipline-focused liaison model that exists in many libraries and the relationship that librarians have with teaching faculty helps to facilitate this embedded approach. 
It is within the liaison context that the academic library has influence to introduce a new learning mandate that contributes to holistic learning and deeper integration of both academic learning skills and information research skills. In 2007, Monash University moved in such a direction when the language and learning support services of the university's Center for the Advancement of Learning and Teaching (CALT) came under the direction of the library.

In assuming responsibility for a broad spectrum of skills development for students, the Library's vision was to take a holistic, student centered approach to providing high quality, cost effective, visible and accessible services, resources, and programs that meet students' learning needs and inspire them to actively participate in the learning process (Smith, 2011, p. 247).

Along with establishing a new approach for front-line query and consultation services, the emphasis on a new organizational teaching structure brought together learning-skills advisers with librarians in disciplinary teams. This new structure allows the library to extend its educational contribution by "bringing together information research and learning skills... to enable students to develop an inextricably linked range of skills for lifelong independent Learning" (Smith, 2011, p. 250). By blending the expertise of librarians and learning-skills advisers and working within a library-faculty partnership model, they have established a collaborative teaching practice that uses the research-skill development (RSD) framework to guide conversations and to "interpret each other's roles, and explore the similarities, differences, and synergies of research-skill development from different professional perspectives" (Torres \& Jansen, 2016, p. 28). 
Similarly, Queensland University of Technology (QUT) established a comparable structure using an integrated academic and information literacies approach as the foundation for reimagining services and a new model of support for student learning in the library.

In redefining services and support, the integrated literacies model entails a strategic shift in functional responsibility for teaching and learning support of academic study skills - a shift which affects all faculties and a significant number of administrative support services across the University. It also intersects with a range of significant QUT-wide student focussed initiatives, such as first year experience, transitions (in, through and out), student portals and e-portfolios (Peacock, 2008, p. 4).

At QUT, the Library Liaison Faculty Teams include liaison librarians, academic skills advisers, and library advisers. Like Monash, these teams are discipline-focused and work with teaching faculty to support the integration of both academic and information literacies into courses and curricula. A middle-tier learning and study support consultation service, called "Study Solutions", includes both librarians and academic skills advisers working together to assistant students in developing these interconnected literacy skills (Derrington, Hayes, Batchelor, \& Peacock, 2011). Each of these domains have its own professional field of discourse, research, and evidence-based practice, and inherent differences do exist. Peacock (2008) points to the similarities and overlap in a number of concept and skills areas, including a core principle "that these skills are most effectively learned and applied when blended with the learning and teaching of other critical skills (such as critical thinking and problem solving) within the context of a discipline" (p. 1). 
Like library information literacy, research into student learning has identified the benefits of embedding generic academic literacy skills into subject-based learning rather than teaching these skills as separate activities (Gunn et al., 2011, p. 1). This notion is even more relevant today given the growing trend in holistic learning and integrated support for student success. Instructors agree that these skills are required and have some expectation that students entering university are already prepared, but that is often not the case. Disciplinary faculty are not necessarily equipped and do not have the background in education, nor do they believe it is their responsibility to address the lack of students' generic academic skills (Gunn et al., 2011, p. 2). Institutions continue to rely on separate specialist units to address the challenges that students face, often as a remedial process rather than through an embedded and developmental skills approach.

The pressures of scale and shifting student demographics may be reaching a tipping point where the embedded approach really needs to take hold. While the separate learning support model works for many of the students that choose to make use of the available services, the results across institutions are inconsistent and therefore less than efficient. The message communicated to students is that these services are optional and the skills assumed. The bottlenecks experienced by support services in libraries and student learning centers at assessment times show that this assumption is unfounded in too many cases (Gunn et al., 2011, p. 8).

The Gunn et al., (2011) case study, using the University of Auckland's Information Literacy programme as an example, asserts that a subject-based, embedded model similar to the library's Business Information Literacy Online initiative can be applied for other academic skills such as 
critical thinking, reflective writing, and relational thinking. Evidence suggests from their study that the educational principles and practical online approach of embedded information literacy instruction provides a foundation for other academic skill development to reach all students.

When generic skills are presented as an integral and assessed part of their course of study, learning is likely to be both uniform and more effective. The workloads of teaching and learning support staff are more manageable with up-front investment rather than demand being addressed on an ad hoc basis at the point of need (Gunn etal., 2011, p. 8).

This assertion is essentially the same as what librarians have maintained regarding information literacy embedded into courses and curricula.

It is time to bring together the evidence that supports integration, the technology tools, learning designs and expertise that allow it to happen, and the compelling education "problem" that needs to be solved, i.e. curriculum design with integrated academic literacy skills to ensure all students, particularly those in large diverse cohorts, can become fully capable graduates (Gunn et al., 2011, p. 9).

\section{A Proximity Perspective}

Although academic librarians and learning specialists come from separate professional domains, both have similar educator roles focused on skill development and literacy strategies supporting student success, learning, and scholarly inquiry. Yet these domains are perceived as being distinct and separate from each other, often reflected in where they report organizationally within the institution. Learning skills are associated with remedial support organized as part of student service units or student success programs, reporting through teaching and learning, 
student services, or as separate support programs within academic units. Conversely, the library has historically had a central "academic" role within the institution, with librarians" professional expertise extending beyond teaching library research skills and information literacy strategies, to include collection expertise and faculty research support.

At the University of Saskatchewan, writing and math/stats support existed within the English and math units, while study skills, not formally offered within any unit, was sporadically provided through student services. With the consolidation and development of these programs as part of the University Learning Center and partner in the LC, the library entered the "farreaching evolution" stage, where according to Beagle (2004) the service profile was no longer library-centric and service delivery altered to be more co-operative and focused on campus-wide priorities. While this is the point where some libraries and librarians might experience discomfort with the services becoming less library-centric, it sets the stage for that "transformational change" that Beagle (2004) refers to within the LC framework where campus-wide learning initiatives, collaborations, integration with core curricula, and new learning paradigms take shape. It is also the stage where the reality of interorganizational collaboration can be most challenging and difficult to achieve due to the lack of shared organizational, cognitive, and cultural understanding.

There is little doubt that co-location and physical proximity within the LC has provided the structure and context for libraries and learning services to work more closely together, but according to Knoben and Oerlemans' (2006) analysis of proximity concepts, geographical proximity alone may not be enough for effective and high-impact collaborative partnerships. Although geographical proximity is most often associated with interorganizational collaboration 
(IOC), these authors suggest that of the seven proximity dimensions - geographical, organizational, cultural, cognitive, institutional, technological, and social - it is the dimensions of geographical, technological, and organizational proximity that are required for strong alliance with potential partners.

The importance of geographic proximity in IOC lies in the fact that small geographical distances facilitate face-to-face interactions (both planned and serendipitous) and, therefore, fosters knowledge transfer and innovation. The main reasoning behind these effects is that short geographical distances bring organizations together, favor interaction with a high level of information richness and facilitate the exchange of, especially tacit, knowledge between actors (Knoben \& Oerlemans, 2006, p. 74).

Yet, according to Knoben and Oerlemans, valuing geographical proximity over organizational and technological proximity is limiting, not as fruitful as it could be if associated with organizational and technological proximity, and does not "harvest the potential gains" (Knobens \& Oerlemans, 2006, p. 87) necessary for a strong collaboration. The importance of organizational and technological proximity for a successful collaboration is reliant on the "need to be similar enough in knowledge bases to be able to recognize the opportunities that the other actor's knowledge gives, but different enough to contribute new knowledge to the IOC" (Knobens \& Oerlemans, 2006, p. 78).

Based on this proximity concept, it can be argued that the geographical proximity dimension aligns with the evolution of the LC model as it moves from "isolated change" to "far-reaching change", but to achieve a "transformational change" toward a new learning paradigm and deeper 
integration; similar to those established at Monash and QUT, organizational proximity is important.

The reasoning behind the importance of organizational proximity for IOC is that IOCs are more efficient and lead to better results when the organizational context of both interacting partners is similar due to the fact that this similarity facilitates mutual understanding. As such, organizational proximity generates a capacity to combine information and knowledge from the collaborative parties, to transfer tacit knowledge and other non-standardized resources between collaborating parties. Thus, this form of proximity is seen as a prerequisite for dyadic and collective learning and in the joint creation of new resources and innovation (Knoben \& Oerlemans, 2006, p. 75)

Boschma and Frenken's (2010) comparable proximity perspective uses five dimensions to explain the structure of networked dynamics and connectivity that has an impact on learning and innovation. Based on their description,

cognitive proximity indicates the extent to which two organizations share the same knowledge base; organizational proximity, the extent to which two organizations are under common hierarchical control; social proximity, the extent to which members of two organizations have friendly relationships; institutional proximity, the extent to which two organizations operate under the same institutions; and geographical proximity, the physical distance or travel time separating two organizations (Boschma \& Frenken, 2010, p. 121). 
Like Knoben and Oerlemans, Boschma and Frenken (2010) state that "geographical proximity may facilitate interactive learning and innovation but that it is neither a necessary nor a sufficient condition for learning and innovation" (p.120). Based on this premise, if geographical proximity facilitates interactive learning then organizational proximity may be required for integrated learning. They suggest that all proximity dimensions are evolutionary and mostly an extension of cognitive and organizational proximity, and that a higher level of innovation is dependent on an optimal level of proximity of all five dimensions.

\section{Organizational Structure, Culture, and Mindset}

The proximity perspective and the dimensions identified provide insight into the LC partnership model based its foundation of geographical proximity, but the extent to which libraries are moving toward new learning services and deeper integration for holistic learning, the other dimensions, in particular organizational proximity, need to be considered. Within the context of the University of Saskatchewan, it is fair to say that the LC structure, with University Learning Center programs and services located in the library, allowed for marginal collaboration based on physical co-location. While geographical, institutional, and to some extent social proximity existed between the library and the University Learning Center, what had been harder to achieve was the ability to transmit knowledge, learn from each other, develop a shared understanding for innovation, and collaboratively develop deeper integration for holistic learning. For this to happen, according to the proximity perspective, organizational proximity with closely linked and overlapping dimensions of cognitive and cultural proximity must also be present. 
When organizational cultures are similar, organizations are expected to interact more easily and with better results, because common interpretations and routines allow organizations to interpret and give meaning to actions without making all these difficult interpretations explicit... The underlying rational is that different conditions, such as organizational culture, customs, norms, and routines influence the way actors see and know the world. In order to communicate and transfer (new) knowledge effectively and efficiently, actors need to have similar (but not necessarily identical) frames of reference (Knoben \& Oerlemans, 2006, pp. 76-77).

With the recent organizational change at the University of Saskatchewan moving learning programs and services under the operations of the university library, these additional proximity dimensions now align and provide a frame to reimagine a new learning mandate together, one that focuses on student learning and academic literacies holistically. The learning paradigm and liaison team approach established by Monash University and QUT is possible because of their organizational proximity and integration. Even with organizational proximity, geographical proximity continues to play a significant role. At Monash, "Co-location has been found to be critical to the success of efforts to foster and develop collaborative partnerships between these two professional groups (the advisers and librarians). Branches where co-location was established at the outset, often through space restrictions, developed shared understanding and collaborative approaches to program development and implementation far more quickly than those where co-location was slower to implement" (Smith, 2011, p. 251). 


\section{A Future Together}

The decision at the University of Saskatchewan to move student learning programs and employees into the organizational structure of the library came about because of university planning priorities. Although not privy to the decision-making process of senior administrators, one might speculate that a different decision could have been to move the learning support programs under the umbrella of Student Services. This would not have been an unusual alignment within an academic setting. Had that happened, it is reasonable to assume that the services and employees would have remained in the existing location within the library as part of the LC partnership, just as they had been. The fact that this was not the approach taken suggests there was some strategic thinking behind the decision to bring student learning under the "academic" umbrella of the library. As Smith (2011) states, "embedding and interconnecting these services within strongly established areas of the university identified with the academic agenda is significantly advantageous and reduces the possibility of marginalisation” (p. 251). And by "bringing together information research and learning skills, the Library's approach to developing programs is to work with students and staff to enable students to develop an inextricably linked range of skills for lifelong independent learning” (p. 250).

A recent report from the Association of College and Research Libraries (2016) highlights evidence of library contributions to student learning and success, supporting the idea that the library "is increasingly recognized as integral to advancing the academic success of students at higher education institutions" (p. 23). Among the findings of the report, alongside benefits of library and information literacy instruction and library use on student success, is reference to the collaborative partnerships that libraries are involved in with other academic units that enhance 
student learning and provide positive benefits for students (Association of College and Research Libraries, 2016). There is no doubt that these collaborations and partnerships, whether part of an LC structure or not, have been instrumental in supporting student learning. The reality is that sometimes the dynamics of different units and the lack of an optimal level of proximity to each other presents barriers or challenges not easily overcome. The evolution toward a learnercentered library and transformation of library spaces through the LC partnership model has paved the way for a new learning mandate for the library. Partnerships will continue to exist and evolve as needed within libraries and across university campuses because of the positive impact it has on students. In order to reframe the learning mandate of the academic library, the next stage of transformation requires libraries to challenge and break down territorial boundaries beyond physical space by recognizing and embracing expertise and knowledge of learning specialists and other professionals as colleagues within the library organization. Sharing in the pursuit of an integrated literacies approach repositions and reaffirms "the importance of academic literacy and information literacy within the University... (Peacock, 2008, p. 10). "At the heart of this promise is a rewarding marriage of two complimentary literacies which, together and separately, assure better learning outcomes, positively affect the student tertiary experience, and ensure capable graduates and capable futures" (Peacock, 2008, p. 11).

... academic libraries are increasingly hubs not only of information literacy related learning, but more broadly of university learning and of student engagement with their learning journey. The integration of learning skills into the library takes this concept of the academic library at the center of university learning to a new point. Bringing together librarians and learning skills advisers with the library structure and service model breaks 
new ground in its integrated approach to holistic skills development and involvement with the student learning experience (Smith, 2011, p. 246).

At the University of Saskatchewan, the library has an opportunity to shape a new direction for student learning on campus, a direction that extends beyond partnership toward deeper collaboration and integration with learning services under library leadership. Looking to the future, the university library will need to redefine its teaching and learning mandate with responsibility more broadly for a range of academic literacies that contribute to and support student success. 


\section{References}

Accardi, M.T., Cordova, M., \& Leeder, K. (2010). Reviewing the library learning commons:

History, models, and perspectives. College \& Undergraduate Libraries, 17(2-3), 310-329. http://dx.doi.org/10.1080/10691316.2010.481595

Association of College and Research Libraries. (2016). Documented library contributions to student learning and success: Building evidence with team-based assessment in action campus projects. Prepared by K. Brown with contributions by K.J. Malenfant. Chicago:

ACRL. Retrieved from http://www.acrl.ala.org/value

Association of College and Research Libraries Research Planning and Review Committee. (2016). 2016 top trends in academic libraries: A review of the trends and issues affecting academic libraries in higher education. College \& Research Libraries News, 77(6), 274-281. Retrieved from http://crln.acrl.org/content/77/6/274.full.pdf

Beagle, D. (1999). Conceptualizing and information commons. The Journal of Academic Librarianship, 25(2), 82-80. https://doi.org/10.1016/S0099-1333(99)80003-2

Beagle, D. (2004). From information commons to learning commons: A white paper for presentation at the University of Southern California Leavey Library Conference. Conference paper. Retrieved from https://www.researchgate.net/publication/263444112 uploaded by Donald Beagle June 2014.

Beagle, D. (2012). The emergent information commons philosophy, models, and 21st century learning paradigms. Journal of Library Administration, 52(6-7), 518-538. http://dx.doi.org/10.1080/01930820903422347. 
Bennett, S. (2009). Libraries and learning: A history of paradigm change. portal: Librarians and the Academy, 9(2), 181-197. https://doi.org/10.1353/pla.0.0049

Boschma, R. \& Frenken, K. (2010). The spatial evolution of innovation networks: A proximity perspective. In R. Boschma \& R. Martin (Eds.), The handbook of evolutionary economic geography (pp. 120 - 135). Cheltenham, UK: Edward Elgar Publishing Limited. http://dx.doi.org/10.4337/9781849806497.00012

Derrington, K., Hayes, G., Batchelor, H., \& Peacock, J. (2011). One more tier, no more tears: Students'perceptions of QUT Library's $2^{\text {nd }}$ tier learning and study support. In J. Thomas (Ed.), $14^{\text {th }}$ Pacific Rim First Year in Higher Education Conference 2011: Design for Student Success. Colourwise Reproductions, Fremantle, Western Australia: QUT. Retrieved from http://eprints.qut.edu.au/50555/

Gunn, C., Hearne, H., \& Sibthorpe, J. (2011). Right from the start: A rationale for embedding academic literacy skills in university courses. Journal of University Teaching \& Learning Practice, 8(1), 110. Retrieved from http://ro.uow.edu.au/jutlp/vol8/iss1/6/

Knoben, J. \& Oerlemans, L.A.G. (2006). Proximity and inter-organizational collaboration: A literature review. International Journal of Management Reviews, 8(2), 71-89. DOI: 10.1111/j.14682370.2006.00121.x

Martin, L. (2008). Transforming ourselves: Developing the multiprofessional team. In M. Weaver (Ed.), Transformative learning support models in higher education: Educating the whole student. London, UK: Facet Publishing.

Peacock, J. (2008). Not yours, not mine... but ours: Integrating learning skills for integrated learning. In Proceedings Dreaming 08, Australian Library and Information Association (ALIA) Biennial 
Conference, Alice Springs, Australia: QUT Digital Repository. Retrieved from http://eprints.qut.edu.au/

Roberts, S., \& Stewart, J. (2008). Towards the holistic university: Working collaboratively for student learning. In M. Weaver (Ed.), Transformative learning support models in higher education: Educating the whole student. London, UK: Facet Publishing.

Smith, L. (2011). Monash University Library and learning: A new paradigm for a new age. Australian Academic \& Research Libraries, 42(3), 246-263. http://dx.doi.org/10.1080/00048623.2011.10722235

Torres, L., \& Jansen, L. (2016). Working from the same page: Collaboratively developing students'research skills across the university. Council of Undergraduate Research Quarterly, 37(1), 26-33. Retrieved from http://www.cur.org/assets/1/23/Fall_issue_fourth_article.pdf

Weaver, M. (Ed.). (2008). Preface. In Transformative learning support models in higher Education: Educating the whole student. London, UK: Facet Publishing.

This is an Accepted Manuscript of an article published by Taylor \& Francis Group in Journal of Library Administration on 09/08/2017, available online:

https://doi.org/10.1080/01930826.2017.1360686 
